\title{
Acute Epidural Hematoma Mimicking an Acute Subdural Hematoma Case Report and Review of the Literature
}

\author{
Bouallag M*, Habchi N, Oumchiche R, Boulaoued W and Djaafer M \\ Department of Neurosurgery, Mustapha PACHA Hospital Algiers, Algeria
}

*Corresponding author: Bouallag Magdouda, Department of Neurosurgery, Mustapha PACHA Hospital Algiers, Algeria, Tel: 02136667426154; Email: nawelmedbio@yahoo.fr

\section{Case Report \\ Volume 3 Issue 2}

Received Date: September 24, 2018

Published Date: October 16, 2018

DOI: $10.23880 /$ nnoaj-16000129

\section{Abstract}

Computed tomography images of the subdural and epidural hematoma are well defined; biconvex and biconcave shape respectively. We report a case of an acute epidural hematoma mimicking acute subdural hematoma. A careful study of imaging is necessary in order to make a correct diagnosis and plan an adequate and early surgical procedure. Early intervention will result in good recovery and any delay can be fatal.

Keywords: Hematoma; Hypodensity; Pneumocephalus; Meningeal Artery

Abbreviations: CT: Computed Tomography; GCS: Glasgow Coma Scale.

\section{Introduction}

Acute extradural hematoma can be crescent shaped on computed tomography and mimic subdural hematoma. We report a case of acute extradural hematoma mimicking an acute subdural hematoma with a detailed CT scan of the hematoma that allowed a diagnostic approach in favor of acute extradural hematoma [1].

\section{Case Report}

A 25 year old man was admitted to our emergency department two hours after a fall from a height of nine (09) meters. He had one episode of vomiting but there was no history of seizures. His general and systemic examinations were within normal limits.

The neurological examination revealed a comatose patient (GCS at 8); pupils were bilaterally equal and normally reactive to light and there was no motor deficit.
The examination of the head reveals a large hematoma of the scalp extended to right frontotemporal region. Urgent body scan was performed. Cerebral CT scan showed spontaneously hyperdense biconcave collection with an area of Hypodensity (pneumocephalus) in the right fronto temporo parietal region. The collection measures 29X17 $\mathrm{mm}$ with associated mass effect of $7 \mathrm{~mm}$. Brain contusion in right temporal region and fracture of fronto parietal bone were associated. A diagnosis of sub dural hematoma was made [2].

A thoracic scan revealed bilateral and multiple chest contusion. Immediate surgery was under taken and a large fronto temporo parietal craniotomy was performed. A large extradural hematoma at fronto temporoparietal region was evacuated. During surgery, there was active bleeding from both fronto temporal fracture and branch of the middle meningeal artery that was controlled with coagulation and gel form after. The bleeding from bone fracture was controlled with bone wax. The outcome was fatal, the patient had and acute respiratory distress syndrome; He had to be kept on ventilator, but ultimately the patient died. 


\section{Neurology \& Neurotherapy Open Access Journal}

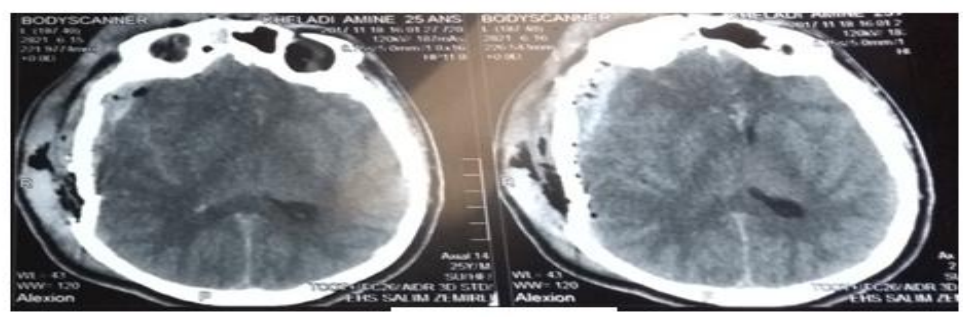

A

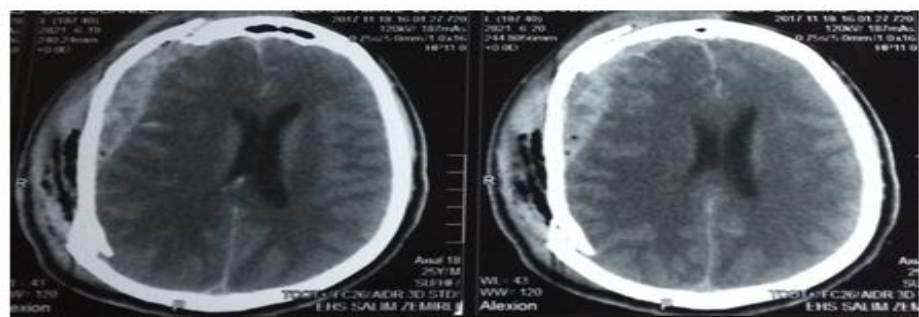

B

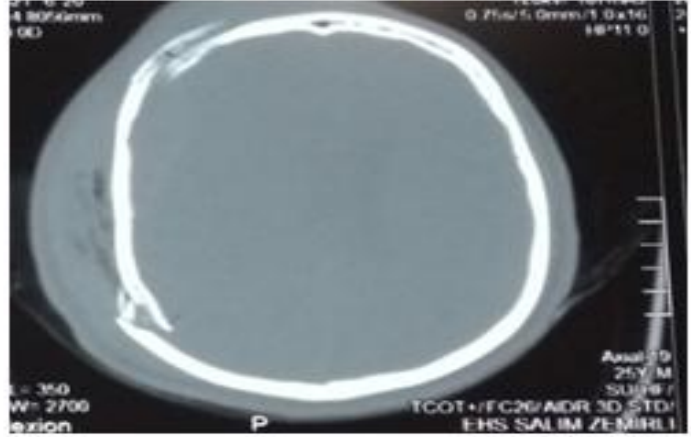

C

Figure 1 (A,B\&C): Cerebral CT scan [3] without contrast showed biconcave collection spontaneously hyperdense with an area of Hypodensity (pneumocephalus) in the right fronto temporoparietal region (A,B). The collection measures 29X17 mm with associated mass effect of $7 \mathrm{~mm}$. Speck of contusion in right temporal region (A) with a fracture of fronto parietal bone and a large sub cutaneous hematoma were associated (C).

\section{Discussion}

Acute extradural hematoma can be confused with an acute subdural hematoma [4] as in the present study case. Careful and correct analysis of images is more necessary because it will helps in surgical planning as extradural hematoma requiring limited exposure; however, an acute subdural hematoma needs a large exposure with duraplasty. Presence of a fracture lines in the vicinity of clot, presence of pneumocephalus in the hematoma and absence of underlying brain lesion on CT scan are features suggestive of extradural hematoma [5]. However, an uncertain diagnosis should not delay surgery as the outcome could be fatal if not.

\section{Conclusion}

The reported clinical case and similar cases found in the literature, although very rare, show how a careful study of imaging (cerebral CT) is very important to make a correct diagnosis. 


\section{Neurology \& Neurotherapy Open Access Journal}

\section{References}

1. Agrawal A (2008) Hyperacute extradural hematoma mimicking acute subdural hematoma. Pak J Neurol Sci 3: 12-13.

2. Braun J, Borovich B, Guilburd JN, Zaaroor M, Feinsod M, et al. (1987) Acute subdural hematoma mimicking epidural hematoma on CT. AJNR Am J Neuroradiol 8: 171-173.

3. Hurvitz SA, Stone LR, Keenan MA, Waters RL (1989) Acute subdural haematoma mimicking an epidural haematoma on a CT scan. Brain Injury 3(1): 63-65.
4. Kato K, Watanbe O, Ozawa Y (1999) Abrupt Exacerbation of Acute Subdural Hematoma Mimicking Benign Acute Epidural Hematoma on Computed Tomography. Neurol Med Chir (Tokyo) 39: 33-35.

5. Miki S, Fujito K, Katayoma W, Sato M, Kamezaki T, et al. (2012) Encapsulated acute subdural hematoma mimicking acute subdural hematoma on computed tomography. Neurol Med Chir (Tokyo) 52: 826-828.

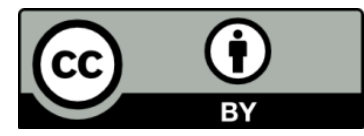

